OESOPHAGUS

\title{
Effect of childhood adversity on health related quality of life in patients with upper abdominal or chest pain
}

\author{
A-M Biggs, Q Aziz, B Tomenson, F Creed
}

Gut 2004;53:180-186. doi: 10.1136/gut.2003.020974

See end of article for authors' affiliations

....................

Correspondence to:

Dr A-M Biggs, Unit of

Chronic Disease

Epidemiology, The

Medical School, University

of Manchester, Oxford Rd,

Manchester M'13 9PT, UK;

Anne-Marie.Biggs@

man.ac.uk

Accepted for publication

1 September 2003
Background and aims: This study assessed whether childhood and current adversities: (a) were more prevalent in patients with functional dyspepsia (FD) or non-cardiac chest pain (NCCP) than in patients with gastro-oesophageal reflux disease (GORD) or ischaemic heart disease (IHD); and (b) predicted health related quality of life in these disorders.

Patients: Cohort study of consecutive attenders to gastroenterology and cardiology clinics in a secondary/ tertiary referral centre.

Methods: Patients were interviewed using the childhood experience of care and abuse and life events and difficulties schedules. Distress was assessed by questionnaire. Outcome was assessed using SF36 at the index clinic visit and six months later.

Results: A total of 133 patients were included (40 NCCP, 43 FD, 29 GORD, and 21 IHD) (67\% response rate). The diagnostic groups did not differ significantly in the proportion reporting childhood adversity $(30 \%)$, ongoing social stress (40\%), lack of a close confidant (14\%), or level of psychological distress. Reported childhood adversity was associated with poor outcome at the index visit (SF36 physical component score: 36.6 (SEM 1.8) v 42.3 (SEM 1.2) for the remainder; $p=0.014$ ). In multiple regression analysis, childhood adversity was a significant independent predictor for patients with functional disorders (NCCP and FD) but not organic disorders (GORD or IHD). Change in SF36 score at six months was determined by age and distress score at the index visit in both groups.

Conclusion: Childhood adversity was common among this consecutive sample but was associated directly with poor outcome only in patients with functional gastrointestinal syndromes. Distress is an important predictor of outcome in all patients. Greatest impairment occurs when lack of social support accompanies reported childhood adversity.
$\mathrm{P}$ atients with functional dyspepsia (FD) and non-cardiac chest pain (NCCP) frequently present to gastroenterologists and may pose a problem of diagnosis and management. ${ }^{1-3}$ Sexual abuse and other psychosocial difficulties may be associated with poor outcome in these patients but it is not clear whether these associations are specific to functional disorders or occur also in patients with organic disease. $^{4}$ In the biopsychosocial model relevant to all gastrointestinal disorders, childhood experiences, social stress, and support and distress during adult life are all seen as potential influences on the experience of illness, its presentation to doctors, and its outcome.

The biopsychosocial model has not been fully tested however as most studies have measured only some of the relevant variables in small or selected samples. Our study included a consecutive series of clinic attenders with the relevant diagnoses, rather than a selected sample, and we used detailed standardised interviews to measure all aspects of childhood experience and recent social stress in order to make more accurate assessments than can be gained by questionnaires alone. We assessed whether social stress, lack of social support, and distress in adulthood explain how or why childhood adversity influences outcome and investigated this notion in patients whose symptoms could be explained by organic disease (gastro-oesophageal reflux disease (GORD) and ischaemic heart disease (IHD)) and those where the symptoms were medically unexplained (FD and NCCP).

We tested the following hypotheses: (1) that patients with NCCP and FD would report a history of childhood adversity, ongoing social stress, and lack of support more often than patients with GORD and IHD; (2) that patients who reported childhood adversity would report worse outcome (greater impairment of health related quality of life) than the remainder; (3) that any association between childhood adversity and outcome would be mediated by social stress, lack of support, and level of distress; and (4) that the same variables would predict health related quality of life whether or not the symptoms were explained by organic disease.

\section{METHODS}

Consecutive new patients were approached at gastroenterology and cardiology outpatient clinics if they were referred with upper abdominal or chest pain. Patients were excluded if they were less than 18 or over 75 years of age, if they had any other serious chronic physical disease, dementia, or psychotic disorder.

Six or more months after the index clinic visit, when all investigations were complete, patients were divided into four diagnostic groups: (1) FD; (2) NCCP; (3) GORD; and (4) IHD. A gastroenterologist (QA) who was blinded to the findings of the psychological and social assessments used the ROME II criteria $^{6}$ to identify FD among patients with normal gastroscopy. Patients were included in the GORD group only if their predominant symptom was heartburn and either oesophagitis had been observed at gastroscopy and/or 24 hour $\mathrm{pH}$ monitoring produced a DeMeester score of more than 14.72. Patients included with IHD all had evidence of abnormal

\footnotetext{
Abbreviations: FD, functional dyspepsia; NCCP, non-cardiac chest pain; GORD, gastro-oesophageal reflux disease; IHD, ischaemic heart disease; HADS, hospital anxiety and depression scale
} 
findings on angiography, myoview scan, or exercise ECG test, and IHD was confirmed by a cardiologist. The cardiologist diagnosed NCCP among patients who had chest pain as their predominant symptom once heart disease had been excluded with one or more of these tests; in addition, of 40 patients, 17 had undergone previous endoscopy to exclude GORD and 13 were taking a proton pump inhibitor which had not relieved the pain.

\section{Assessments}

Sociodemographic data were collected regarding age, sex, ethnicity, years of education, socioeconomic status, and marital status. Duration of symptoms was noted and severity of chest/abdominal pain was rated on a scale of 0 (no pain) to 100 (most severe pain).

\section{Childhood adversity}

The childhood experience of care and abuse (CECA) interview $^{7}$ was administered shortly after the index clinic visit by a single interviewer (AMB). This retrospective semi-structured interview uses behavioural evidence of the seriousness of childhood events to avoid influence by the respondent's current mental state. The rating of severity was made by a panel of three experienced researchers who were blinded to the patient's diagnosis. Only adversities rated as 1 for "marked" or 2 "moderate" are included in this report (see appendix). Antipathy covers parental dislike, criticism, and hostility towards the child. Neglect includes physical aspects, such as inadequate clothing or food, and emotional aspects such as lack of interest in the child's well being. Physical abuse takes into account the age of the child, the nature of the abuse, and the injury inflicted; usually an implement such as a belt or stick is involved. Sexual abuse involves some physical contact. Psychological abuse includes incidents such as extreme rejection and calculated cruelty. The identity and location of the perpetrators are recorded. During this interview respondents were asked for details of any serious illness or deaths among first degree relatives during their childhood.

\section{Possible mediators \\ Social stress}

The life events and difficulties schedule ${ }^{8}$ is another detailed semi-structured interview; information was gathered for the year preceding the clinic appointment. Ratings of severity were made by a panel of trained researchers who were blinded to the patient's diagnosis. Only severely threatening events (for example, diagnosis of cancer in a family member, marital separation) and marked ongoing social difficulties (for example, ongoing severe illness in a family member or very severe marital problems) are quoted in this paper. In the analysis, the total severity score of marked ongoing social difficulties were used. ${ }^{8}{ }^{9}$ Ongoing difficulties related to the subject's own health were excluded.

\section{Social support}

Social support was measured firstly as unmarried status, particularly separated, widowed, or divorced, and also in terms of availability of a confidant. The latter is someone with whom the individual has a close, intimate, and confiding relationship.

\section{Distress}

The hospital anxiety and depression scale (HADS) ${ }^{10}$ includes seven items each of anxiety and depression. It was designed for use in medical patients as it excludes questions concerning bodily symptoms (for example, fatigue, weight loss) that might directly result from a physical illness and is a valid and reliable measure. ${ }^{11}{ }^{12}$ In this paper, the total (anxiety plus depression) score is used and referred to in the text as "distress score".

\section{Outcome measure}

The 36 item short form health survey (SF36) is a widely used generic measure of health related quality of life. ${ }^{13}$ It includes eight subscales but only the physical and mental summary scores are quoted in this report. ${ }^{14}$ The population norm for these scores is 50 and a low score indicates poor health (a score of 40 represents one standard deviation below the norm). ${ }^{15}$ SF36 scores may be influenced by severity of gastrointestinal disorders, depression, ${ }^{16-19}$ and cardiac disease. $^{20}$

The size of our sample was based on a power calculation using data from a primary care sample ${ }^{21} ; 24$ patients were required in each group to detect a difference in childhood adversity at the $5 \%$ level of significance with $80 \%$ power. All patients gave written consent for the study. The study had ethics permission from the local health authorities in Central Manchester (ref No CM/96/0169) and Salford and Trafford (ref No 99185).

\section{Statistical analysis}

The statistical package SPSS (version 10.1 for Windows 1998) was used. Parametric tests ( $t$ test, ANOCOVA) were used as all of the main variables were normally distributed. Reported adverse experiences in childhood were treated as childhood risk factors. Social stress during the year prior to the index visit, lack of social support, and distress were treated as mediating variables between childhood adversity and outcome. Health related quality of life (SF36 physical and mental component summary scores) at the time of the index clinic visit and SF36 change in health score after six months of follow up were regarded as outcome variables.

The first analyses compared the four diagnostic groups and differences were assessed using the $\chi^{2}$ test or ANOCOVA, controlling for age, sex, and ethnic group. The second set of analyses compared patients with and without childhood adversity using the same tests; ANOCOVA controlled for age, sex, socioeconomic status, and diagnosis. The ANOCOVA was repeated, controlling, in addition, for the presence/absence of a confidant and marital status. This procedure was repeated for patients with organic disorders (GORD and IHD) and functional disorders (FD and NCCP) separately.

To assess whether childhood adversity had a direct effect on outcome, stepwise linear regression with mean substitution was used. With the SF36 physical component score at the index visit as the dependent (outcome) variable, the independent variables entered were age, sex, years of education, social class, marital status (single and widowed/ separated/divorced status as separate variables), death or serious illness of a family member during childhood, any reported childhood adversity, presence of a confidant, marked social difficulties score, and distress score. This procedure was repeated with the SF36 mental component score as the dependent variable. Separate analyses were run for patients with symptoms explained by organic disease (GORD and IHD) and medically unexplained syndromes (FD and NCCP).

In order to determine the variables that predicted change in health related quality of life after six months of follow up, a logistic regression analysis was performed. The variables entered were identical to those listed in the previous paragraph; the dependent variable was SF36 change in health recorded at follow up expressed as "same or better" or "worse". 
Table 1 Sociodemographic characteristics of the sample by diagnosis

\begin{tabular}{|c|c|c|c|c|c|c|c|}
\hline & $\begin{array}{l}\text { GORD }(\%) \\
(n=29)\end{array}$ & $\begin{array}{l}\text { FD }(\%) \\
(n=43)\end{array}$ & $\begin{array}{l}\text { NCCP (\%) } \\
(n=40)\end{array}$ & $\begin{array}{l}\text { IHD (\%) } \\
(n=21)\end{array}$ & $\chi^{2}$ & df & $\mathrm{p}$ Value \\
\hline Mean (SD) age (y) & $49.8(12.1)$ & $47.9(12.8)$ & $50.1(10.1)$ & $58.4(9.0)$ & $\begin{array}{l}p=0.007 \\
(t \text { test })\end{array}$ & & \\
\hline Women & $14(48)$ & $26(60.5)$ & $26(65)$ & $6(29)$ & 8.52 & 3 & 0.036 \\
\hline Single & $2(7)$ & $4(9)$ & $2(5)$ & $3(14)$ & & & \\
\hline Married & $22(76)$ & $34(79)$ & $28(70)$ & 12 (57) & & & \\
\hline Widowed/separated/divorced & $5(17)$ & 5 (12) & $10(25)$ & $6(29)$ & 5.52 & 6 & 0.48 \\
\hline White Europeans & $29(100)$ & $42(98)$ & $35(87.5)$ & $21(100)$ & 8.76 & 3 & 0.033 \\
\hline Middle class & $15(52)$ & $21(49)$ & $15(37.5)$ & $13(62)$ & 3.56 & 3 & 0.31 \\
\hline$>12$ y education & $15(52)$ & 27 (63) & $16(40)$ & $8(38)$ & 5.63 & 3 & 0.13 \\
\hline Access to confidant & $26(90)$ & $38(88)$ & $33(83)$ & $17(81)$ & 1.34 & 3 & 0.72 \\
\hline \multicolumn{8}{|l|}{ Traumatic experiences } \\
\hline $\begin{array}{l}\text { Severe life event or difficulty in last } \\
\text { year (excl own health) }\end{array}$ & $15(52)$ & $25(58)$ & $15(37.5)$ & $6(29)$ & 6.7 & 3 & 0.83 \\
\hline $\begin{array}{l}\text { Death of family member during } \\
\text { childhood }\end{array}$ & $7(24)$ & $14(33)$ & $9(22.5)$ & $4(19)$ & 1.80 & 3 & 0.61 \\
\hline $\begin{array}{l}\text { Seriously ill family member during } \\
\text { childhood }\end{array}$ & $14(48)$ & $20(46.5)$ & $25(62)$ & $9(43)$ & 3.11 & 3 & 0.38 \\
\hline \multicolumn{8}{|l|}{ No of childhood adversities } \\
\hline None & $20(69)$ & $32(74)$ & $26(65)$ & $15(71)$ & 2.05 & 6 & 0.92 \\
\hline 1 & $5(17)$ & $4(9)$ & $8(20)$ & $3(14)$ & & & \\
\hline 2 or more & $4(14)$ & $7(16)$ & $6(15)$ & $3(14)$ & & & \\
\hline $\begin{array}{l}\text { Reported childhood adversity and } \\
\text { lacked a confidant }\end{array}$ & $1(3.4)$ & $2(4.7)$ & $6(15)$ & $1(4.8)$ & 4.65 & 3 & 0.12 \\
\hline
\end{tabular}

\section{RESULTS}

\section{Sample}

Of 231 eligible patients, $33(14.2 \%)$ refused outright and a further $43(18.6 \%)$ were later unavailable for interview. Of 155 subjects interviewed, 22 subjects were later excluded because they had another diagnosis (for example, peptic ulcer) or failed to fulfil our criteria for a diagnosis of GORD or IHD. Of those included, 40 had NCCP, 43 FD, 29 GORD, and 21 IHD ( 15 had angina, six had myocardial infarction). The median duration of symptoms prior to the clinic visit was 18 , 12, 11.5, and 13 months for GORD, FD, NCCP, and IHD, respectively $(\mathrm{p}=0.48$, Kruskal Wallis test).

Forty $(30 \%)$ participants had experienced one or more forms of childhood adversity: 30 (23\%) had experienced antipathy from one or more parent during childhood, 19 (14.3\%) had experienced neglect, 27 (20\%) physical abuse, 10 (7.5\%) psychological abuse, and $11(8 \%)$ sexual abuse. Twenty (15\%) had experienced multiple adversities (two or more). Thirty four $(26 \%)$ had experienced the death of a parent or sibling before the subject was aged 17 years. At the time of the clinic visit, 19 (14\%) lacked a confiding relationship and $53(40 \%)$ had one or more ongoing marked social difficulties; 27 (20\%) had experienced a severely threatening life event in the previous year.

The SF36 physical and mental component scores at the index clinic visit were 40.6 (SD 12.0) and 44.2 (SD 10.9), respectively. Patients off sick at the time of their clinic visit had significantly lower (more impaired) physical component scores compared with the remainder (33.6 (SEM 2.1) $v 44.2$ (SEM 1.1); $\mathrm{p}<0.001$ after adjustment for age, sex, socioeconomic status, and diagnosis); corresponding SF36 mental component scores were 38.8 (SEM 2.2) and 45.0 (SEM 1.2) adjusted $(\mathrm{p}=0.017)$.

\section{Comparison of the diagnostic groups}

The groups were broadly similar in demographic characteristics but, in view of the differences shown in table 1 , subsequent comparisons between diagnostic groups were adjusted for age, sex, and ethnic group (table 2). There were no significant differences between the four diagnostic groups in the proportion who reported childhood adversity (of any type), serious illness, or death of a parent or sibling during childhood (table 1). In terms of potential mediating variables, there were no significant differences in terms of availability of a confidant and scores for ongoing marked social difficulties and distress (HADS score) (tables 1, 2).

\section{Outcome variables}

The IHD group had the lowest scores (greatest impairment) on the SF36 physical component score at the time of the index visit and patients with this diagnosis and NCCP were

Table 2 Mean (SEM) scores for anxiety/depression, health anxiety, and illness worry by diagnostic group, controlling for age, sex, and ethnic group

\begin{tabular}{|c|c|c|c|c|c|}
\hline & GORD $(n=29)$ & FD $(n=43)$ & $\operatorname{NCCP}(n=40)$ & IHD $(n=21)$ & p Value (ANCOVA \\
\hline Pain score & $62.4(5.1)$ & $59.0(4.3)$ & $54.7(4.5)$ & $48.1(6.3)$ & 0.31 \\
\hline HAD total & $11.3(1.5)$ & $15.7(1.2)$ & $15.3(1.3)$ & $16.6(1.8)$ & 0.054 \\
\hline Marked social difficulties score & $1.5(0.4)$ & $2.2(0.4)$ & $1.7(0.4)$ & $1.9(0.5)$ & 0.61 \\
\hline \multicolumn{6}{|l|}{ Outcome variables } \\
\hline SF36 physicalt & $44.8(2.2)$ & $41.6(1.8)$ & $38.9(1.9)$ & $35.8(2.7)$ & 0.046 \\
\hline SF36 mental† & $47.8(2.0)$ & $44.1(1.7)$ & $43.5(1.8)$ & $40.6(2.5)$ & 0.14 \\
\hline Follow up SF36 change in health & & & & & $\chi^{2}$ \\
\hline Same/improved & $24(82.8 \%)$ & $30(78.9 \%)$ & $20(58.8 \%)$ & $6(30.0 \%)$ & 18.83 \\
\hline Worse & $5(17.2 \%)$ & $8(21.1 \%)$ & $14(41.2 \%)$ & $14(70.0 \%)$ & $<0.0005$ \\
\hline
\end{tabular}

FD, functional dyspepsia; NCCP, non-cardiac chest pain; GORD, gastro-oesophageal reflux disease; IHD, ischaemic heart disease; HADS, hospital anxiety and depression scale.

†SF36 physical component summary score and SF36 mental component summary score. 
Table 3 Sociodemographic data of patients with and without a reported history of childhood adversity

\begin{tabular}{|c|c|c|c|}
\hline & $\begin{array}{l}\text { No reported childhood } \\
\text { adversity }(\%)(n=93)\end{array}$ & $\begin{array}{l}\text { Reported childhood } \\
\text { adversity (\%) ( } n=40)\end{array}$ & OR $(95 \% \mathrm{Cl})$ \\
\hline Mean (SD) age $(y)$ & $51.9(12.0)$ & $47.6(10.6)$ & $p=0.056$ ( $t$ test) \\
\hline Single & $7(7)$ & $4(10)$ & \\
\hline Married & 73 (79) & $23(58)$ & \\
\hline Widowed/separated/divorced & $13(14)$ & $13(32)$ & $6.82(2)[0.033]^{\star}$ \\
\hline Women & $49(53)$ & $23(57)$ & $0.82(0.39-1.74)$ \\
\hline White Europeans & $90(97)$ & 37 (92) & $2.4(0.47-12.6)$ \\
\hline Middle class & $52(56)$ & $12(30)$ & $2.96(1.34-6.52)$ \\
\hline$>12$ y education & $48(52)$ & $18(45)$ & $0.77(0.36-1.6)$ \\
\hline $\begin{array}{l}\text { Access to confidant } \\
\text { Traumatic experiences. }\end{array}$ & $84(90)$ & $30(75)$ & $0.32(0.12-0.87)$ \\
\hline $\begin{array}{l}\text { Iraumatic experiences: } \\
\text { Severe event or marked difficulty in } \\
\text { last year (excl own health) }\end{array}$ & $35(37.6)$ & $18(45)$ & $1.36(0.64-2.87)$ \\
\hline Death in family during childhood & $25(27)$ & $9(22)$ & $0.79(0.33-1.89)$ \\
\hline $\begin{array}{l}\text { Seriously ill family member during } \\
\text { childhood }\end{array}$ & $41(44)$ & $27(67)$ & $2.63(1.21-5.73)$ \\
\hline
\end{tabular}

more likely to report that their condition was worse six months later (table 2). There were no significant differences in mental component score at the index visit.

\section{Childhood adversity}

Patients who reported childhood adversity were less likely than the remainder to be middle class, married, or have a close confiding relationship (table 3 ). They reported more serious illness in an immediate family member during childhood but not more deaths (table 3). They did not experience more social difficulties during the year before clinic attendance (table 4 ).

Potential mediators-lack of a close confidant, distress, and social stress

Those who reported childhood adversity were more likely to lack social support in adulthood and this relationship followed a "dose-response" pattern. Patients who reported two or more childhood adversities were least likely to have a close confidant $\left(\chi^{2}=8.63, \mathrm{df}=2, \mathrm{p}=0.013\right)$ and most likely to be separated, divorced, or widowed $\left(\chi^{2}=7.53, \mathrm{df}=2\right.$, $\mathrm{p}=0.023)$ (fig 1 ).

Patients who reported childhood adversity had higher distress scores than the remainder (table 4), especially in those patients who also lacked a confidant (table 5). This combination of reported childhood adversity and lack of a confidant occurred most often in patients with NCCP but the difference was not significant (table 1, bottom row).

\section{Outcome variables}

Patients who reported childhood adversity had lower scores (more impaired) on the SF36 physical and mental component scores at the index visit (table 4). These differences were significant after adjustment for age, sex, socioeconomic status, and diagnosis but not after controlling for marital status or availability of a confidant. Lack of a confidant and reported childhood adversity had an additive effect on outcome (fig 2). Reported childhood adversity was not associated significantly with worse health at the six month follow up.

\section{Health related quality of life in patients with organic and functional disorders}

In patients who had organic disease (GORD and IHD), which explained their pain, the mean SF36 physical component score adjusted for age, sex, socioeconomic status, confidant, and marital status was similar for patients with and without childhood adversity (40.3 (SEM 1.7) and 40.7 (SEM 2.6); $\mathrm{p}=0.89)$. Corresponding data for patients with functional disorders (FD and NCCP) were 35.9 (SEM 2.6) for those with reported childhood adversity and 42.7 (SEM 1.6) for those without $(\mathrm{p}=0.038)$.

\section{Variables determining impaired health related quality of life at the time of the index consultation}

In the linear regression analysis, including patients with organic disease, distress score and widowed/separated/ divorced status were the two independent predictors of the

\begin{tabular}{|c|c|c|c|}
\hline & $\begin{array}{l}\text { No reported childhood } \\
\text { adversity }(n=93)^{*}\end{array}$ & $\begin{array}{l}\text { Reported childhood } \\
\text { adversity }(n=40)^{*}\end{array}$ & p Valuet \\
\hline Pain score (VAS) & $55.3(2.9)$ & $59.9(4.4)$ & 0.391 \\
\hline HAD total ("distress score") & $13.5(0.8)$ & $17.7(1.2)$ & 0.006 \\
\hline Marked social difficulties score & $2.3(0.4)$ & $1.7(0.2)$ & 0.22 \\
\hline \multicolumn{4}{|l|}{ Outcome measures } \\
\hline SF36 physicalł & $42.3(1.2)$ & $36.7(1.8)$ & 0.014 \\
\hline SF36 mental $\ddagger$ & $45.5(1.1)$ & $40.9(1.7)$ & 0.031 \\
\hline \multicolumn{4}{|l|}{ Follow up SF36 change in health } \\
\hline Same/improved & 61 (69.3\%) & $19(57.6 \%)$ & $\tilde{1} .48$ \\
\hline Worse & $27(30.7 \%)$ & $14(42.4 \%)$ & $p=0.156$ \\
\hline
\end{tabular}

*Values are mean (SEM).

†Adjusted for age, sex, socioeconomic status, and diagnosis.

†SF36 physical component summary score and SF36 mental component summary score.

VAS, visual analogue scale; HADS, hospital anxiety and depression scale. 


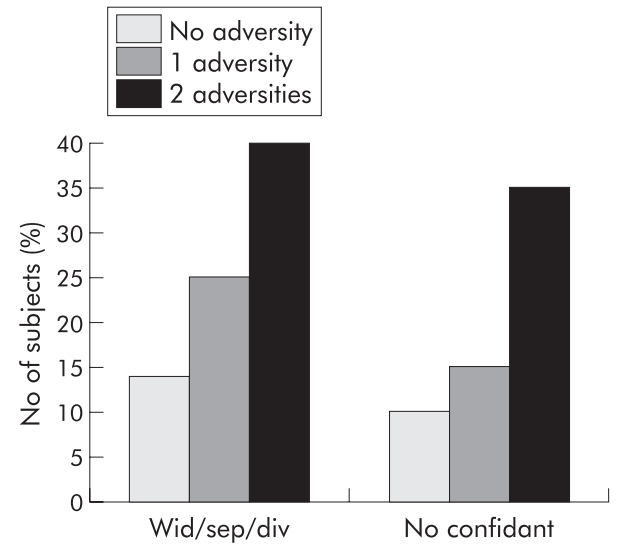

Figure 1 Percentage of patients lacking social support by number of childhood adversities. Wid/sep/div, widowed, separated, or divorced.

SF36 physical component score at the index visit $(42.7 \%$ of variance explained). In the analysis with functional disorders, distress score, age, and reported childhood adversity were the three independent predictors $(23 \%$ variance explained). For both groups, distress score was the first variable selected. In a similar analysis to predict the mental component score of SF36, the level of distress (HADS score) was the only variable selected in the final model.

\section{Variables predicting change in health related quality of life after six months of follow up}

Six month follow up data were available for 121/133 (91\%) patients; one had died and the remainder did not respond to repeated requests to return the questionnaire. Eighty patients reported that their symptoms were the same or better at follow up; their SF36 pain score decreased by 6.0 (SEM 2.8). Forty one patients reported their symptoms were worse; their SF36 pain score increased by 6.1 (SEM 4.0). In a logistic regression using the same independent variables as before, change in health after six months of follow up was predicted by older age and high distress (table 6).

\section{DISCUSSION}

We rejected our first hypothesis that patients with FD and NCCP would report more childhood adversity, less social support, and greater distress than patients with similar pain, which could be explained by organic disease. We had not expected this finding but two previous large studies found no difference in the proportion of people with organic or functional gastrointestinal disorders who reported a history of abuse. ${ }^{22}{ }^{23}$ We did not find the high prevalence of abuse in
GORD previously reported in a small number of volunteers at a tertiary referral centre. ${ }^{24}$

Our second hypothesis was largely upheld. Like others, we found that patients who reported childhood adversity had a worse outcome than the remainder. ${ }^{23}{ }^{24}$ This was challenged by Talley and Boyce ${ }^{25}$ who called for more rigorous methodology in recording childhood experiences, use of a less highly selected population, and greater consideration of possible confounding variables. Our study overcame these criticisms with the best available childhood interview ${ }^{7}$ and analysis of possible confounders. We found childhood adversity to be quite common in this population (30\%) but severe sexual abuse (that is, that which involved touching or rape) was relatively rare $(8 \%)$, although comparable with the other study of consecutive attenders $(6.9 \%)^{22}$ and much lower than the prevalence figures in the selected samples in tertiary referral centres. ${ }^{24} 26$

Our third and fourth hypotheses were mostly not upheld; the effect of childhood adversity was not mediated by lack of social support, rather the effect of these two forms of social adversity was additive. In the multiple regression analysis, childhood adversity had an independent effect on outcome in patients with functional disorders (FD and NCCP). With this exception, the predictors of health related quality of life were similar in patients with organic or functional disorders-a high level of distress was the main predictor of health related quality of life in all diagnoses both at the index consultation and six months later.

Our patients who reported childhood adversity were also more likely to lack social support and experience high levels of distress in adulthood. These relationships followed a "dose response" relationship (table 5), suggesting causality, ${ }^{27}$ and we report, for the first time in these patients, that this combination of childhood adversity and lack of satisfactory social support in adulthood life is more important than abuse alone in predicting impaired health related quality of life. ${ }^{28}$ This combination occurred rarely in our sample but is presumably overrepresented in tertiary clinic settings where health related quality of life is most impaired. Those people who reported a history of childhood adversity but who had been able to form close confiding relationships in adulthood did not have such poor outcomes.

Our data therefore offer support to the psychological and social parts of the biopsychosocial model of gastrointestinal disorder. ${ }^{5}$ Whereas reported childhood adversity is an important variable, which directly affects outcome in patients with functional gastrointestinal disorders, it may affect outcome in all patients through the mediating variable of distress. These findings need to be replicated in larger samples but we believe this model may be more productive than the search for associations between specific psychosocial

Table 5 Mean (SEM) scores for mediating and outcome variables - patients with and without a reported history of childhood adversity and/or availability of confidant

\begin{tabular}{|c|c|c|c|c|}
\hline & $\begin{array}{l}\text { No reported childhood } \\
\text { adversity and confidant } \\
\text { available }(n=84)\end{array}$ & $\begin{array}{l}\text { Reported childhood } \\
\text { adversity or no confidant } \\
\text { available ( } n=39 \text { ) }\end{array}$ & $\begin{array}{l}\text { Reported childhood adversity } \\
\text { and no confidant available } \\
(\mathrm{n}=10 \text { ) }\end{array}$ & p Value* \\
\hline \multicolumn{5}{|l|}{ Symptom experience } \\
\hline Pain score (VAS) & $53.5(3.0)$ & $60.8(4.4)$ & $67.1(8.7)$ & 0.198 \\
\hline HAD total ("distress score") & $13.0(0.8)$ & $17.2(1.2)$ & $20.4(2.4)$ & 0.001 \\
\hline \multicolumn{5}{|l|}{ Outcome variables } \\
\hline SF36 physical $\dagger$ & $42.7(1.2)$ & $37.5(1.8)$ & $34.3(3.7)$ & 0.017 \\
\hline SF36 mentalt & $46.4(1.2)$ & $40.8(1.7)$ & $37.9(3.4)$ & 0.006 \\
\hline $\begin{array}{l}\text { Follow up SF36 change in health } \\
\text { Same/improved }\end{array}$ & $551696 \%$ & $22(629 \%$ & $3(429 \%)$ & $\chi^{2}$ \\
\hline $\begin{array}{l}\text { Same/ Improved } \\
\text { Worse }\end{array}$ & $24(30.4 \%)$ & $13(37.1 \%)$ & $4(57.1 \%)$ & $\mathrm{p}=0.318$ \\
\hline
\end{tabular}

*Adjusted for age, sex, socioeconomic status, and diagnosis.

†SF36 physical component summary score and SF36 mental component summary score. 


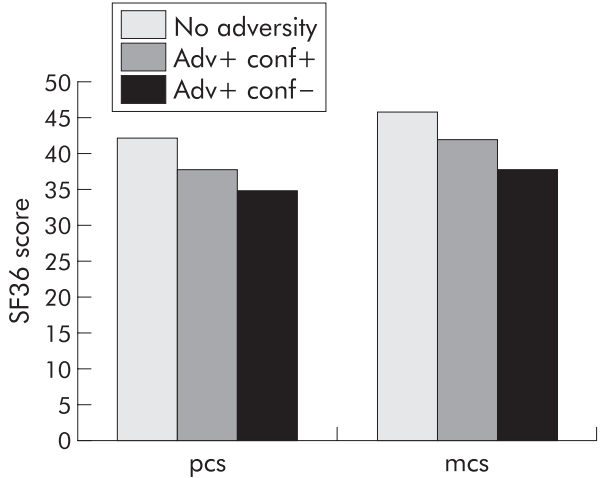

Figure 2 SF36 physical (pcs) and mental (mcs) component scores by adversity (Adv) and no confidant (conf) in adulthood.

features and functional gastrointestinal diagnosis. ${ }^{29}$ Further work is required to examine the mechanisms whereby adversity and distress affect health related quality of life but it is notable that distress score was significantly associated with each of the four SF36 subscale scores, which comprise the physical component score (pain, physical function, role limitation physical, and health perceptiondata not shown). It is likely that psychological and physiological processes interact to produce health related quality of life as in irritable bowel syndrome and inflammatory bowel disease. ${ }^{16} 1830$

The strengths of this study include the consecutive nature of the sample, the detailed interviews for childhood and recent adversity, which were performed blind to diagnosis, and the fact that all our patients were complaining of a similar symptom-pain in the chest or upper abdomenwhich was diagnosed with considerable accuracy. Potential weaknesses of the study include the response rate, which was not as high as we had hoped although it is comparable or better than many other studies of this type. Another weakness of this study was the relatively limited number of subjects; this was inevitable because of the detailed and time consuming interviews, which we regarded as essential for this research. Only 17 of the patients with NCCP were investigated for GORD, although a further 13 were taking proton pump inhibitors without relief of symptoms. If the remaining 10 patients were removed from the analyses, the overall results remained the same. To have insisted on full investigations for all would have changed this study to one of selected patients rather than the consecutive series that we preferred.

Our follow up period was insufficient to document completely the response to treatment; some patients would have been successfully treated for GORD after six months whereas others would still be waiting for surgical treatment for heart disease. Our measure of outcome at six months was crude, but was necessary in view of the need to have a single outcome measure for a variety of conditions.

Our results may not be generalised to all patients with these conditions because of the long duration of symptoms (12-15 months prior to the index visit). This reflects the UK health system in which patients receive the majority of their medical treatment in primary care and only those with persistent or worrying symptoms are referred to this clinic. Our study was therefore concerned with factors associated with poor outcome after $12-18$ months of symptoms; it is during this time period that distress is associated with poor outcome-different factors might predict outcome in more short lived symptoms. Our measure of health related quality of life was generic, not disease specific; this was necessary because of the several conditions that were being studied. It was self-rated but its validity is seen in the people who were off sick and in a larger prospective study of irritable bowel syndrome. $^{31}$

Finally, it is important to note that the multivariate analyses to predict SF36 physical component score explained only $23-43 \%$ of the variance, which means that there are other factors involved in determining these outcomes. Our study did not include physiological measures, which would presumably have added additional variance to the model.

In summary, we have shown that childhood adversity is not more common in patients with functional than organic disease leading to upper abdominal or chest pain. The negative effect of childhood adversity on outcome is mediated principally through distress but there is some evidence of a direct relationship, especially when childhood adversity is accompanied by poor social support in adulthood. This pattern is important in people with functional disorders but distress is an important predictor of outcome in all patients.

The clinical implications are twofold. Firstly, it may be less important for gastroenterologists to ask about childhood adversity than to ask about levels of distress and the nature of the closest relationships. Secondly, appropriate treatment for distress and any help with problems in close relationships may improve health related quality of life as has been shown in dyspepsia ${ }^{32}{ }^{33}$ and severe irritable bowel syndrome. ${ }^{33}$ This study paves the way for testing more specific hypotheses in relation to the biopsychosocial model for patients with functional gastrointestinal disorders, including biological studies of gut-brain axis and further intervention studies.

\section{ACKNOWLEDGEMENTS}

This research was supported by UK Medical Research Council, UK North West Regional R\&D Directorate and Functional Gastrointestinal disorders working group. Dr Aziz is an MRC Clinician Scientist.

Table 6 Logistic regression analysis with six month SF36 change in health outcome as the dependent variable; variables selected in the final model are listed below with beta coefficient

\begin{tabular}{llllll}
\hline & Variable selected & Beta (SE) & p Value & Odds ratio & $\begin{array}{l}\% \text { Correctly } \\
\text { classified }\end{array}$ \\
\hline Organic disease (GORD, IHD) & & & & & \\
Step 1 & Age & -0.078 & 0.019 & $0.92(0.87-0.99)$ & 61.2 \\
Step 2 & HAD total score & -0.094 & 0.027 & $0.91(0.84-0.99)$ & 71.4 \\
$\quad$ Constant & & 5.964 & 0.004 & & \\
Functional disorders (FD, NCCP) & Age & -0.070 & 0.029 & $0.94(0.88-0.99)$ & 73.6 \\
$\quad$ Step 1 & HAD total score & -0.152 & 0.001 & $0.86(0.78-0.94)$ & 76.4 \\
Step 2 & & 6.827 & 0.001 & & \\
$\quad$ Constant & & & & & \\
\hline
\end{tabular}




\section{Authors' affiliations}

A-M Biggs, B Tomenson, F Creed, School of Psychiatry and Behavioural Sciences, Rawnsley Building, Manchester Royal Infirmary, Manchester, UK

Q Aziz, Department of Gastroenterology, Clinical Sciences Building, Hope Hospital, Salford, UK

\section{APPENDIX}

\section{Physical abuse rated 2}

Subject, female, aged from four years. Her father hit her 7-8 times at least once per week, with the strap end of a belt. He was always drunk when he hit her; on one occasion aged five years she was punched but never seriously injured.

\section{Sexual abuse rated 1}

Subject, male, aged 6-12 years, was raped by his brother almost every night; his brother used physical violence to enforce his cooperation. Unable to confide in anyone as he also suffered antipathy from his mother, who showed no affection, treated him "like a stranger...not like a son at all" and threw him out of the family home aged 13 years.

\section{Psychological abuse rated 1}

Subject, female, aged five years, witnessed her brother aged 4 years drowning. Her mother blamed her for the death and refused to look after her, so she lived with a succession of relatives. At aged 15 years she received a parcel of her brother's bootees and other baby items and a note from her mother: "I want you to keep these as a reminder of what you've done".

\section{Neglect rated 2}

Subject, female, was brought up by grandmother who became ill with cancer when $\mathrm{S}$ was aged 10 years. She was no longer able to take care of S, who had to do the shopping and other household chores and to get herself to and from school.

\section{Antipathy from father rated 1}

Subject, female, aged 16 years. She had to hand over her entire earnings to her father and to act as "household drudge". Her father's manner was cold and distant and he wouldn't talk to S except to order her to do something. The rest of the family ate before S came back from work. She was never included in family activities.

\section{REFERENCES}

1 Achem SR, DeVault KR. Unexplained chest pain at the turn of the century. Am J Gastroenterol 1999;94:5-8.

2 Talley N. Scope of the problem of functional digestive disorders. Eur J Surg Suppl 1998; 582:35-41.

3 Talley NJ, Silverstein MD, Agreus L, et al. AGA technical review: evaluation of dyspepsia. American Gastroenterological Association. Gastroenterology 1998:114:582-95.

4 Felitti VJ. Long-term medical consequences of incest, rape, and molestation. South Med J 1991;84:328-31

5 Drossman DA. Presidential address: gastrointestinal illness and the biopsychosocial model. Psychosom Med 1998;60:258-67.
6 Drossman DA, Corazziari E, Talley NJ, et al, eds. Rome II: the functional gastrointestinal disorders. McLean, VA: Degnon Associates, 2000.

7 Bifulco A, Brown GW, Harris TO. Childhood experience of care and abuse (CECA): a retrospective interview method. J Clin Psychol Psychiatry 1994:35:1419-35.

8 Brown GW, Harris TO. Social origins of depression: a study of psychiatric disorder in women. London: Tavistock, 1978.

9 Brown GW, Adler Z, Bifulco A. Life events, difficulties and recovery from chronic depression. Br J Psychiatry 1988;152:487-98.

10 Zigmond AS, Snaith RP. The hospital anxiety and depression scale. Acta Psychiat Scand 1983;67:361-70.

11 Herrmann C. International experiences with the hospital anxiety and depression scale - a review of validation data and clinical results. J Psychosom Res 1997;42:17-41.

12 Johnston M, Pollard B, Hennessey P. Construct validation of the hospital anxiety and depression scale with clinical populations. J Psychosom Res 2000:48:579-84

13 Ware JE, Sherbourne CD. The MOS 36-item short-form health survey (SF-36). Med Care 1992;30:473-83.

14 Ware JE, Kosinski M, Keller SK. SF-36 physical and mental health summary scales: a user's manual. Boston, Mass: The Health Institute, New England Medical Center, 1994.

15 Ware JE, Kosinski M, Bayliss MS, et al. Comparison of methods for the scoring and statistical analysis of SF-36 health profile and summary measures: summary of results from the medical outcomes study. Med Care 1995;33:AS64-79.

16 Creed F, Ratcliffe J, Fernandez L, et al. Health-related quality of life and health care costs in severe, refractory irritable bowel syndrome. Ann Intern Med 2001;134(Suppl):860-8.

17 Creed F, Morgan R, Fiddler M, et al. Depression and anxiety impair healthrelated quality of life and are associated with increased costs in general medical inpatients. Psychosomatics 2002;43:302-9.

18 Guthrie E, Jackson J, Shaffer J, et al. Psychological disorder and severity of inflamatory bowel disease predict health-related quality of life in ulcerative colitis and Crohn's disease. Am J Gastroenterol 2002;7:1994-9.

19 Whitehead WE, Burnett CK, Cook EW iii, et al. Impact of irritable bowel syndrome on quality of life. Dig Dis Sci 1996:41:2248-53.

20 Spertus JA, Winder JA, Dewhurst TA, et al. Monitoring the quality of life in patients with coronary artery disease. Am J Cardiol 1994;74:1240-4

21 Craig TKJ, Brown GW. Goal frustration and life events in the aetiology of painful gastrointestinal disorder. J Psychosom Res 1984;28:411-21.

22 Talley NJ, Fett SL, Zinsmeister AR. Self-reported abuse and gastrointestinal disease in outpatients: association with irritable bowel-type symptoms. Am J Gastroenterol 1995;90:366-71.

23 Drossman DA, Zhiming LI, Leserman J, et al. Health status by gastrointestinal diagnosis and abuse history. Gastroenterology 1996;110:999-1007.

24 Scarinci IC, McDonald-Haile J, Bradley LA, et al. Altered pain perception and psychosocial features among women with gastrointestinal disorders and history of abuse: a preliminary model. Am J Med 1994;97:108-18.

25 Talley NJ, Boyce P. Abuse and functional gastrointestinal disorders: what is the link and should we care? Gastroenterology 1996;110:1301-4.

26 Drossman DA, Leserman J, Nachman G, et al. Sexual and physical abuse in women with functional or organic gastrointestinal disorders. Ann Intern Med 1990;113:828-33.

27 Kraemer HC, Stice E, Kazdin A, et al. How do risk factors work together? Mediators, moderators and independent, overlapping and proxy factors. Am J Psychiatry 2001;158:848-56.

28 Luecken LJ. Attachment and loss experiences during childhood are associated with adult hostility, depression and social support. J Psychsom Res 2000;49:85-91.

29 Bennett EJ, Piesse C, Palmer K, et al. Functional gastrointestinal disorders: psychological, social and somatic features. Gut 1998:42:414-20.

30 Naliboff BD, Balice G, Mayer EA. Psychosocial moderators of quality of life in irritable bowel syndrome. Eur J Surg Suppl 1998;583:57-9.

31 Hamilton J, Guthrie E, Creed F, et al. A randomised controlled trial of psychotherapy in patients with chronic functional dyspepsia. Gastroenterology 2000;119:661-9.

32 Calvert EL, Houghton LA, Cooper P, et al. Long-term improvement in functional dyspepsia using hypnotherapy. Gastroenterology 2002;123:1778-85

33 Creed F, Fernandes L, Guthrie E, et al. The cost-effectiveness of psychotherapy and paroxetine for severe irritable bowel syndrome. Gastroenterology 2003; 124:303-20 